\title{
Exploring the Carbon Deposition Mechanism on Ni/Gd Ceria Catalysts
}

\author{
Ethan Lawrence and Peter Crozier
}

School for the Engineering of Matter, Transport and Energy, Arizona State University, Tempe Arizona 85287-6106

Solid oxide fuel cells (SOFCs) can be operated using carbonaceous fuels by adding an internal reforming layer to the anode. Developing intermediate temperature devices $\left(500^{\circ} \mathrm{C}-750^{\circ} \mathrm{C}\right)$ would solve many issues that currently limit SOFC applications [1]. Ni/Gd co-doped ceria anode materials have shown promise for operating at intermediate temperatures and maintaining good catalytic performance [2]. Ni serves as the fuel reforming catalyst but may also result in carbon deposition onto the Ni metal surface [3]. Carbon deposition becomes a major problem as carbon can coat the surface and render the Ni inactive. Carbon can also dissolve into the bulk Ni metal and cause stress which may lead to fractures and failure [3]. Ceria has been shown to oxidize carbon on its surface through release of oxygen atoms from the lattice [2]. Therefore, Ni/Gd co-doped ceria may inhibit carbon deposition while maintaining good reforming activity. To investigate this process, we have performed reforming tests over a model Ni/Gd doped ceria catalyst used to reform methane. Ex situ and in situ environmental transmission electron microscopy (ETEM) is employed to investigate the atomic level processes that result in carbon formation.

A $15 \mathrm{wt} \% \mathrm{Gd}, 8 \mathrm{wt} \% \mathrm{Ni}$ co-doped ceria reforming catalyst was prepared using a spray drying technique. During spray drying, an aqueous solution of Ce-nitrate, Gd-nitrate, and Ni-nitrate was sprayed into a reaction chamber where it comes in contact with a stream of air heated to approximately $350^{\circ} \mathrm{C}$. The water evaporates rapidly producing a nanoparticle powder. The powder is then calcined at $500^{\circ} \mathrm{C}$ and $700^{\circ} \mathrm{C}$ for 4 hours to produce the reforming catalyst. XRD was performed on the fresh catalyst to confirm that GDC and $\mathrm{NiO}$ phases were present with average phase sizes of $17 \mathrm{~nm}$ and $25 \mathrm{~nm}$, respectively. These particles were then loaded into an ISRI RIG-150 microreactor system through which $\mathrm{CH}_{4}$ and $\mathrm{O}_{2}$ gases were flowed while the temperature was ramped up to $900^{\circ} \mathrm{C}$. The Varian $\mathrm{GC}-450$ was used to analyze the exit gases. The $\mathrm{NiO}$ reduced to $\mathrm{Ni}$ around $730^{\circ} \mathrm{C}$ and activated the catalyst for partial oxidation of methane (POM). The exit gases were analyzed using a Varian GC-450 gas chromatography system. In order to study carbon deposition, temperature was ramped up to $800^{\circ} \mathrm{C}$ to ensure the catalyst was activated and then held at $675^{\circ} \mathrm{C}$. To induce the methane decomposition reaction, the $\mathrm{O}_{2}$ flow rate was reduced. A high carbon loading sample and low carbon loading sample were created. The initial $\mathrm{CH}_{4}: \mathrm{O}_{2}$ flow rate was $32: 16 \mathrm{cc} / \mathrm{min}$ for both samples. For the high carbon loading sample, the $\mathrm{O}_{2}$ flow rate was reduced in a stepwise manner over 3 hours to $2 \mathrm{cc} / \mathrm{min}$. The low carbon loading sample had the $\mathrm{O}_{2}$ flow rate decreased directly to $4 \mathrm{cc} / \mathrm{min}$ and held for a half hour.

Imaging and energy dispersive x-ray spectroscopy (EDS) were performed using a JEOL 2010F scanning transmission electron microscope (STEM) to investigate the morphology and structure of the material, as well as the location of carbon deposition on the catalyst. Typical fresh catalyst particles (Figure 1) show a GDC region with a $\mathrm{NiO}$ particle sitting on the surface. During the POM reaction, these NiO particles are reduced to metallic $\mathrm{Ni}$ which then acts as the reforming catalyst. In the low carbon loading sample, graphite formation (lattice spacing of $3.35 \AA$ ) was seen on Ni particles that were separated from the particle aggregates as seen in Figure 2. In areas where Ni particles were in intimate contact with GDC, small to no carbon formation was seen as in Figure 3. This suggests that the proximity of the Ni particles to the 
GDC regions influences the carbon formation. In the high carbon loading sample, carbon was seen in the form of graphite and carbon nanotubes growing on Ni and GDC particles shown in Figure 4.

In order to further study carbon deposition, in-situ TEM experiments will be performed under reactive gas conditions; results will be presented. Cermets made from these Ni/Gd doped ceria catalysts will also be studied. In situ ETEM will be performed to directly observe the structure of the cermet and the spatial distribution of carbon deposition under oxygen deficient and oxygen rich conditions [4].

\section{References:}

[1] Brett, D. J. L. et al, Chemical Society reviews 37 (2008), p. 1568-78.

[2] Zhou, Y. et al, Physical Chemistry Letters 9 (2010), p. 1447.

[3] Atkinson, A. et al, Nature Materials 3 (2004), p. 17-27.

[4] We gratefully acknowledge support of NSF grant DMR-1308085 and ASU's John M. Cowley Center for High Resolution Electron Microscopy.

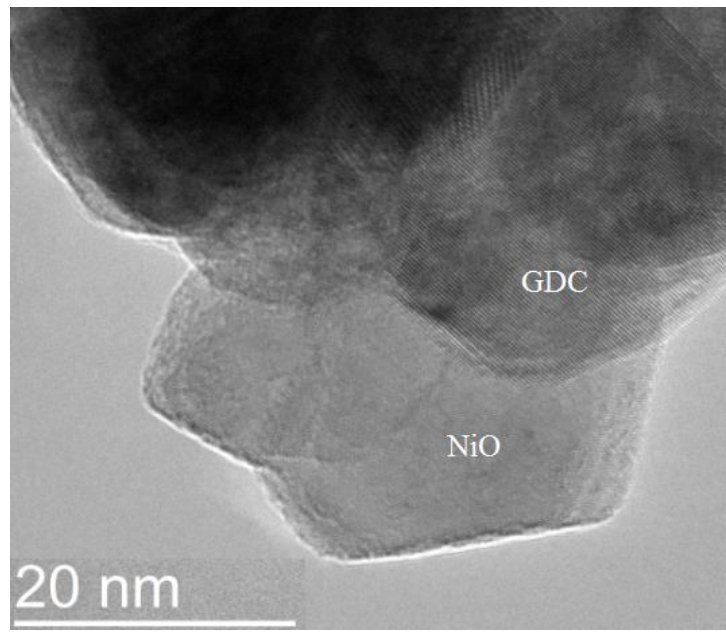

Figure 1. TEM image of fresh catalyst showing $\mathrm{NiO}$ on GDC particles.

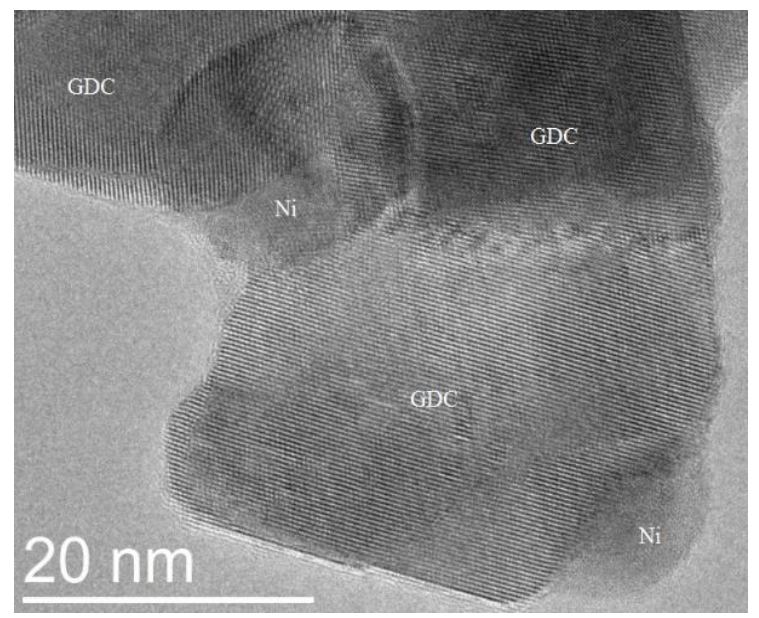

Figure 3. TEM image of low carbon loading catalyst showing Ni particles in close proximity to GDC regions.

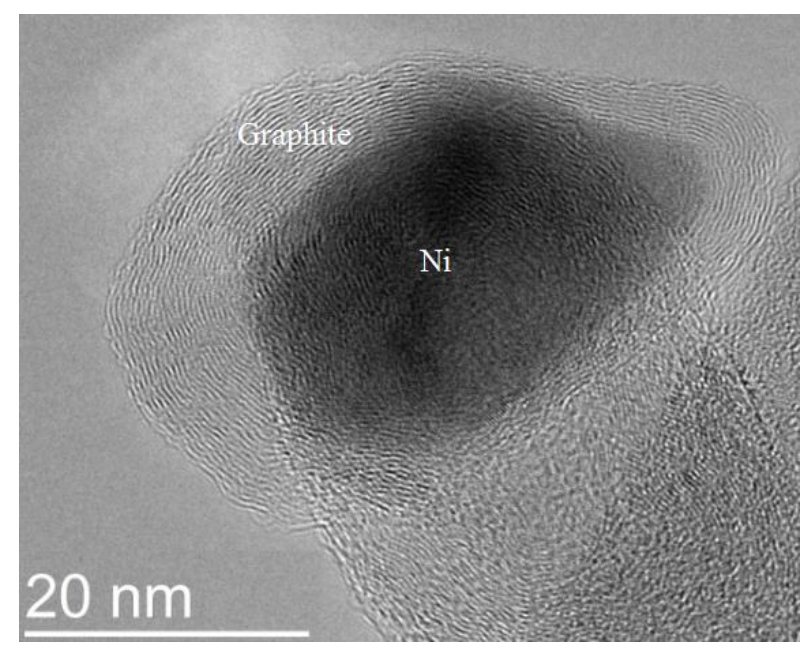

Figure 2. TEM image of low carbon loading catalyst where graphite has formed on a Ni particle.

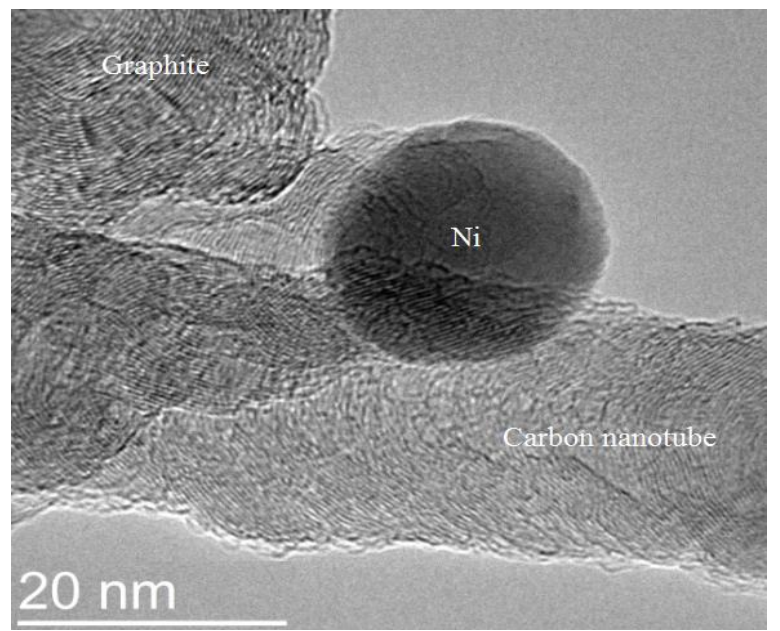

Figure 4. TEM image of high carbon loading catalyst where graphite and carbon nanotubes have formed. 